\title{
Metal phosphide catalysts for the hydrotreatment of non-edible vegetable oils
}

M. Consuelo Alvarez-Galvan*, Gema Blanco-Brieva, Maricarmen CapelSanchez, Silvia Morales-delaRosa, Jose M. Campos-Martin ${ }^{\star}$ and Jose L. G. Fierro

Sustainable Energy and Chemistry Group. Instituto de Catálisis y Petroleoquímica, CSIC, Marie Curie, 2, Cantoblanco, 28049 Madrid, Spain. http://www.icp.csic.es/eqsgroup/

${ }^{*}$ CORRESPONDING AUTHOR FOOTNOTE

J. M. Campos-Martin, e-mail: j.m.campos@icp.csic.es

M. C. Alvarez-Galvan, e-mail: c.alvarez@icp.csic.es

Fax: +34 915854760 


\section{Abstract}

Silica-supported catalysts of nickel, cobalt, iron, molybdenum, and tungsten metal phosphides $\left(\mathrm{NiP} / \mathrm{SiO}_{2}, \mathrm{CoP} / \mathrm{SiO}_{2}, \mathrm{FeP} / \mathrm{SiO}_{2}, \mathrm{MoP} / \mathrm{SiO}_{2}\right.$, and $\left.\mathrm{WP} / \mathrm{SiO}_{2}\right)$ with a metal-loading of $15 \mathrm{wt} \%$, were synthesized by reduction of the corresponding phosphite precursors. The catalysts were characterized by $\mathrm{N}_{2}$ adsorption-desorption, X-ray diffraction (XRD), $\mathrm{CO}$ pulse chemisorption, $\mathrm{NH}_{3}$ temperature programmed desorption ( $\left.\mathrm{NH}_{3}-\mathrm{TPD}\right)$, and $\mathrm{X}$-ray photoelectron spectroscopy (XPS). The activity of these catalysts was measured at $573 \mathrm{~K}$, a liquid flow of $0.3 \mathrm{~mL} \cdot \mathrm{min}^{-1}$, a pressure of $2.0 \mathrm{MPa}$ and a $\mathrm{H}_{2} /$ liquid ratio of 300 in a three-phase, trickle-bed reactor in the hydrotreatment of methyl laurate. The $\mathrm{MoP} / \mathrm{SiO} 2$ catalyst was found to exhibit the best catalytic performance based on its higher active phase dispersion as measured by XRD, CO chemisorption and XPS analyses, along with its moderate acidity, which is higher with respect to the other studied catalysts. The reaction conditions using the $\mathrm{MoP} / \mathrm{SiO}_{2}$ catalyst, the most active and selective to $\mathrm{C}_{12}$ and $\mathrm{C}_{11}$ hydrocarbons, were optimized. Optimal results can be obtained under the following conditions: 573 $\mathrm{K}, 2.0 \mathrm{MPa}$, and a liquid flow of $0.3 \mathrm{~mL} \cdot \mathrm{min}^{-1}$. Moreover, long-run experiments showed that the $\mathrm{MoP} / \mathrm{SiO}_{2}$ catalyst exhibits stable catalytic behavior for at least $96 \mathrm{~h}$

Keywords: Green Diesel; Hydrogenation; Vegetable Oil; Metal phosphides; hydrotreatment 


\section{Introduction}

The fast development of the global economy is accelerating the consumption of energy resources, while fossil fuel reserves are depleting rapidly, and stringent environmental regulations have led to interest in biomass, being abundant and readily available, as a renewable energy source. The utilization of biomassderived fuels has several advantages over the use of conventional fuels, such as reduction in greenhouse gas emissions, localized production, and favorable economics of utilization. One very interesting alternative is the use of vegetable oils, oily residues and fats, because these materials have a low oxygen content. Traditionally, the vegetable oils and fats are converted to biodiesel by transesterification [1-4]. An interesting alternative to biodiesel production is the catalytic hydrotreating of oils and fats into hydrocarbon-based fuel (Green Diesel) [4]. Hydrotreatment removes the oxygen of triglycerides, esters and free acids molecules via decarboxylation, decarbonylation or hydrodeoxygenation (HDO) processes to yield mainly $n$-alkanes [5-12]. Furthermore, isomerization and cracking of the hydrocarbon chains can also be significant, depending on the characteristics of the catalysts, and these reactions contribute to upgrading the fuel properties.

Catalysts employed in the hydrotreatment process are basically constituted by a metal supported on a high surface area oxide support. The metallic function will be responsible of the hydrodeoxygenation of the oil and the hydroisomerization, therefore, selection of the metal is very important. Several kinds of catalysts were employed for this reaction, mainly based on reduced transition metals or sulfided catalysts such as CoMoS or NiMoS, or noble metals. The most active catalysts are based on noble metals, which have a high activity in the 
hydrotreatment of free acids and methyl esters, but the price of the catalysts is very high. The metal sulfides are a good alternative, and these catalysts show good activity in the hydrotreatment of triglycerides. However, a byproduct of the reaction is water, which makes it necessary to feed a sulfide source to maintain the stability of the metal sulfides $[2,13,14]$. An interesting alternative is the use of catalysts based on transition metal phosphides. They are very active for hydrotreatment reactions, their electronic structure is quite similar to that of noble metals [15-19], they are quite stable and resistant to the presence of water [16], and they have a lower cost than catalysts based on noble metals. The synthesis of the supported phosphide catalysts could be carried out by a standard phosphate method [15] or by a phosphite method [19-21]. The first one has two activation steps in the preparation method: i) calcination of precursors and ii) reduction and phosphide formation. While the second method has only one activation step, reduction and phosphide formation without calcination, the phosphorous precursor has a lower oxidation state, and consequently, phosphide formation occurs at a lower temperature [19-21]. The support usually employed in the preparation of supported metal phosphides is based on silica because a low acidity oxide favors the formation of metal phosphides due to the low interaction between the support and the precursors [19], and silica has a high surface area and a mesoporous texture that promotes dispersion [17, 22, 23].

Several studies of the hydrotreatment of vegetable oils with metal phosphides have been reported, see for instance [16-18, 24], but in all of them, the metal phosphides were prepared with the phosphate method. To our knowledge no study has used the phosphite method for catalysts synthesis. In this work, we 
prepare catalysts using the phosphite method, characterize the catalyst, and test the activity of the phosphide-based catalysts in the hydrotreatment of methyl laureate (a model compound for a vegetable oil) to produce green diesel fraction. The characterization results have been correlated with catalytic activity results to determine those properties that have a role on the catalytic performance.

\section{Experimental}

\subsection{Catalysts preparation}

The catalysts were prepared by hydrogen reduction of different transition metals (Ni, Co, Fe, Mo and $\mathrm{W}$ ) dihydrogen phosphites, using commercial silica cylindrical pellets as the support. As indicated in literature [25], for this preparation method, there is no need for calcination and a lower reduction temperature is required. Moreover, it has been proven to form very active and stable catalysts for hydrotreating reactions.

Catalysts (15 wt\% metal) were prepared by successive incipient wetness impregnations of silica, adding stoichiometric amounts of phosphorous acid $\left(\mathrm{H}_{3} \mathrm{PO}_{3}\right.$, SIGMA-ALDRICH $\left.99 \%\right)$ and the corresponding transition metal precursors $\left(\mathrm{Ni}(\mathrm{OH})_{2}\right.$ Sigma-Aldrich, $\mathrm{Co}\left(\mathrm{NO}_{3}\right)_{2} \cdot 6 \mathrm{H}_{2} \mathrm{O} \quad 99 \%$ Sigma-Aldrich, $\mathrm{Fe}\left(\mathrm{NO}_{3}\right)_{3} \cdot 9 \mathrm{H}_{2} \mathrm{O} \quad 98 \%$ Sigma-Aldrich, $\quad\left(\mathrm{NH}_{4}\right)_{6} \mathrm{Mo}_{7} \mathrm{O}_{24} \cdot 4 \mathrm{H}_{2} \mathrm{O} \quad 99 \%$ Merck, $\left(\mathrm{NH}_{4}\right)_{10} \mathrm{~W}_{12} \mathrm{O}_{42} \cdot 5 \mathrm{H}_{2} \mathrm{O}$ PROLABO) to obtain the following phosphides: $\mathrm{Ni}_{2} \mathrm{P}$, $\mathrm{Co}_{2} \mathrm{P}, \mathrm{FeP}, \mathrm{MoP}$ and $\mathrm{WP}$. The precursors were dissolved in $2 \mathrm{~mL}$ of water per gram of silica and added dropwise over commercial pelletized silica $(1.5 \mathrm{~mm}$ cylindrical pellets, Saint Gobain-NORPRO, SS 61138); this procedure was 
repeated 5 times. Then, the obtained dihydrogen phosphites $\left(\mathrm{M}\left(\mathrm{HPO}_{3} \mathrm{H}\right) \times ; \mathrm{M}=\right.$ $\mathrm{Ni}, \mathrm{Co}, \mathrm{Fe}, \mathrm{Mo}, \mathrm{W} ; \mathrm{x}=1$ or 2)) were dried in an oven at $333 \mathrm{~K}$ overnight.

Impregnation was followed by reduction of the precursors to obtain the corresponding phosphides. The activation was carried out ex situ, in a fixed-bed quartz reactor, using a hydrogen flow $\left(1000 \mathrm{~mL}(\mathrm{NTP}) \mathrm{min}^{-1}\right)$ at a heating rate of $3 \mathrm{~K} \cdot \mathrm{min}^{-1}$ and kept at the reduction temperature for $2 \mathrm{~h}$. A low heating ramp is critical to avoid the formation of phosphates impurities during reduction [25]. On the other hand, the high flow rate of hydrogen has been chosen because it favors the quick removal of water formed during the reduction process [25, 26], leading to the formation of smaller particles as well as favoring diffusion of volatile $\mathrm{P}$ species onto nickel the particles to form the phosphide. The reduction temperatures were different for each precursor and were chosen from the reduction data previously published for this systems and preparation method $[25,26]$. being $853 \mathrm{~K}$ for the nickel and molybdenum precursors, $873 \mathrm{~K}$ for the tungsten one, $993 \mathrm{~K}$ for the cobalt one, and $1053 \mathrm{~K}$ for the iron counterpart. Subsequently, the phosphides were cooled to room temperature in $\mathrm{N}_{2}(200 \mathrm{~mL}$ (NTP) $\min ^{-1}$ ) and passivated in a $\mathrm{N}_{2}$ stream containing $0.5 \% \mathrm{O}_{2}$ for $2 \mathrm{~h}$.

\subsection{Catalysts characterization}

Textural properties were determined from the adsorption-desorption isotherms of nitrogen, recorded at $77 \mathrm{~K}$ with a Micromeritics Asap2420. Specific area was calculated by applying the $B E T$ method to the relative pressure $\left(\mathrm{P}^{\mathrm{P}} \mathrm{P}^{0}\right)$ range of the isotherms between 0.03 and 0.3 , and taking a value of $0.162 \mathrm{~nm}^{2}$ for the cross-section of an adsorbed nitrogen molecule at $77 \mathrm{~K}$. Pore size distributions 
were computed by applying the BJH model to the desorption branch of the nitrogen isotherms.

X-ray diffraction profiles of samples were recorded with a X'Pert Pro PANalytical diffractometer equipped with a CuKa radiation source $(\lambda=0.15418 \mathrm{~nm})$ and X'Celerator detector based on RTMS (Real Time Multiple Strip). The samples were ground and placed on a stainless steel plate. The diffraction patterns were recorded in steps over a range of Bragg angles $(2 \theta)$ between 4 and $90^{\circ}$, at a scanning rate of $0.02^{\circ}$ per step and an accumulation time of $50 \mathrm{~s}$. Diffractograms were analyzed with the X'Pert HighScore Plus software. The mean domain size was then estimated from X-ray line width broadening using the Scherrer equation. Width ( $\mathrm{t}$ ) was taken as the full width at half maximum intensity of the most intense and least overlapped peak.

Metal dispersions were determined by $\mathrm{CO}$ pulse chemisorption. $\mathrm{CO}$ uptakes were measured using a Micromeritics Autochem II 2920 apparatus. A 100-200 mg portion of reduced and passivated sample was loaded in the reactor and reduced in a $\mathrm{H}_{2}$ flow $\left(50 \mathrm{~mL} \cdot \mathrm{min}^{-1}\right)$ at $723 \mathrm{~K}$ for $2 \mathrm{~h}\left(\operatorname{ramp}, 10 \mathrm{~K} \cdot \mathrm{min}^{-1}\right)$. Afterwards, the sample was cooled to $313 \mathrm{~K}$, while it was flushed with a He flow $\left(50 \mathrm{~mL} \cdot \mathrm{min}^{-1}\right)$. When the TCD signal was stable, pulses of $\mathrm{CO}(75 \mu \mathrm{L})$ were passed through the samples until the areas of consecutive pulses were constant. The total CO uptake was then calculated.

dispersion $(\%)=\frac{\text { Co uptake }\left(\frac{\text { mmoles }}{g}\right)}{\text { Metal loading }\left(\frac{m \text { moles }}{g}\right)}$

$\mathrm{NH}_{3}$-TPD was carried out using a Micromeritics Autochem II 2920 apparatus. A 110-170 $\mathrm{mg}$ of sample was reduced with a $\mathrm{H}_{2}$ flow $\left(50 \mathrm{~mL} \cdot \mathrm{min}^{-1}\right)$ at $723 \mathrm{~K}$ and then cooled to room temperature. Next, an $\mathrm{NH}_{3}(5 \%) / \mathrm{He}$ flow $\left(15 \mathrm{~mL} \cdot \mathrm{min}^{-1}\right)$ was 
passed through the sample for $30 \mathrm{~min}$ at $373 \mathrm{~K}$. In the next step, at $373 \mathrm{~K}$, the sample was swept with a He flow $\left(25 \mathrm{~mL} \cdot \mathrm{min}^{-1}\right)$ for $30 \mathrm{~min}$ to remove the physically adsorbed $\mathrm{NH}_{3}$. Afterwards, $\mathrm{NH}_{3}$-TPD was performed in a He flow (25 $\mathrm{mL} \cdot \mathrm{min}^{-1}$ ) at a heating rate of $15 \mathrm{~K} \cdot \mathrm{min}^{-1}$, from 373 to $973 \mathrm{~K}$. The desorbed $\mathrm{NH}_{3}$ was detected by a TCD.

XPS measurements were registered using a VG Scientific Escalab 200R spectrometer equipped with a hemispherical electron analyzer and an $\mathrm{Al} \mathrm{K \alpha}(\mathrm{h} v$ $\left.=1486.6 \mathrm{eV}, 1 \mathrm{eV}=1.6302 \times 10^{-19} \mathrm{~J}\right) 120 \mathrm{~W} \mathrm{X}$-ray source. The analyses were performed after an in situ reduction of the samples at $723 \mathrm{~K}$ for $2 \mathrm{~h}$. The area of the peaks was estimated by calculating the integral of each peak after smoothing and subtraction of an S-shaped background and fitting of the experimental curve to a mixture of Gaussian and Lorentzian lines of variable proportions. All binding energies $(B E)$ were referenced to the $C$ 1s signal at $284.6 \mathrm{eV}$ from the carbon contamination of the samples to correct for the charging effects. Quantification of the atomic fractions on the sample surface was obtained by integration of the peaks with appropriate corrections for sensitivity factors [27].

\subsection{Catalytic Activity Test}

The catalysts were tested for the hydrotreatment of methyl laurate. The reactor operated in trickled-bed mode in parallel flow and at high pressure, ensuring that the three phases, gas-liquid-solid, are in close contact. The reduced/passivated catalyst pellets without dilution was activated by reduction "in situ" at $723 \mathrm{~K}$ at atmospheric pressure, then the reactor was cooled to the reaction temperature and pressurized. The reaction conditions employed were: 
553-593 K, 1.0-3.0 MPa, liquid flow 0.2-0.4 mL. $\mathrm{min}^{-1}$, and $\mathrm{H}_{2} /$ liquid ratio of 300 . The gas phase products were analyzed by an on-line Inficon 3000 micro-GC equipped with 4 channels, two $5 \mathrm{~A}$ molecular sieves, a Porpaplot $\mathrm{Q}$ and a Stawilwax. The liquid products were collected and analyzed offline by gas chromatography with an Agilent 7890A GC equipped with a DB-5MS and an FID detector.

\section{Results and discussion}

Characterization of catalysts was carried out on catalysts previously reduced and passivated (see experimental section). The reduction temperature was chosen according to the reduction data previously published for these compounds and preparation method [25, 26].

The textural properties analysis of the support and reduced catalysts shows that all samples display a type IV isotherm with an $\mathrm{H} 1$ hysteresis loop, typical of mesoporous materials consisting of agglomerates or a compact packing of nearly uniform, regularly ordered microspheres [28, 29]. As a preliminary observation, all the catalysts show similar textural properties, BET surface area, pore volume and average pore diameter (Table 1). Reduced catalysts exhibit lower BET surface area and pore volume than the starting silica support, which would suggest partial pore structure blockage by the incorporation of the phosphide active phase. The BET surface areas of the reduced catalysts are between $120-185 \mathrm{~m}^{2} \mathrm{~g}^{-1}$. Figure 1 shows the pore size distributions of reduced catalysts and the bare silica support. All of them have a symmetrical distribution with an average pore size approximately $12 \mathrm{~nm}$. 
The XRD patterns of the catalysts precursors (dihydrogen phosphites of the corresponding transition metals) are totally amorphous, while the corresponding activated catalysts (after reduction and passivation) show diffraction peaks (Figure 2). All XRD patterns present a broad diffraction at $2 \theta$ angle in the range $10-35^{\circ}$ which is characteristic of amorphous silica [30]. Average domain sizes have been calculated by the Scherrer equation, and the obtained values, together with the phases obtained for each catalyst, are reported in Table 2. The selected diffraction lines are the more intense and non-overlapped.

The $\mathrm{NiP} / \mathrm{SiO}_{2}$ sample, with a high metal loading, presents higher intensity diffraction lines. The metallic character of $\mathrm{Ni}_{2} \mathrm{P}$ due to the short $\mathrm{Ni}-\mathrm{Ni}$ metal distance in the $\mathrm{Ni}_{2} \mathrm{P}$ phase, close to that of the pure metal, could activate hydrogen, favoring the reduction [25]. The formation of nickel hydride is ascribed to $\mathrm{P}$ loss, as phosphine, during the reduction [16]. In the cobalt phosphide silica catalyst, the peaks corresponding to $\mathrm{Co}_{2} \mathrm{P}$ phases consist of overlapped diffraction lines. Thus, it was not possible to determine the average domain size of this crystalline phase. In the case of the molybdenum phosphide counterpart, diffraction lines corresponding to molybdenum phosphide are not observed. This indicate that this phase is very well-dispersed, having a mean crystallite size below 2-3 $\mathrm{nm}$. Concerning the other catalysts, the average crystallite size of prepared phosphides presents the following trend: $\mathrm{Ni}>\mathrm{Fe}>\mathrm{W}$ $>$ Co. For nickel phosphide catalyst only the stoichiometry $\mathrm{M}: \mathrm{P}=2$ was found, for the tungsten phosphide catalyst, only the stoichiometry $\mathrm{M}: \mathrm{P}=1$ was observed, on the contrary, MP and $\mathrm{M}_{2} \mathrm{P}$ phases were observed in the XRD patterns of $\mathrm{Co}$ and Fe phosphide catalysts. 
As observed in Table 1 and Table 2, except for CoP and MoP, average crystalline domains (or crystallite sizes) are far above the average pore size of the catalysts, but the pore diameter range is quite broad as it is usual in a silica gel. Assuming that the size of metal phosphide particles is similar to the average crystalline domain, for all prepared phosphides the pore structure can accommodate all prepared metal phosphides inside of pores of the catalyst support.

$\mathrm{CO}$ pulse chemisorption was used to determine the number of exposed surface metal sites. It has been assumed that each active site adsorbs one $\mathrm{CO}$ molecule [19], since CO is mainly linearly bound to the metal site on phosphides [31]. Table 2 presents the numbers of surface metal atoms (from the CO uptakes) and dispersions for the prepared catalysts. The dispersions have been calculated by dividing the number of surface metal atoms by the nominal loadings. The obtained dispersion values were low, indicating poor distribution of the active phase on the support, which agrees with previous results and is typical of metallic compounds supported on silica [32].

The uptakes range from 0.2 to $114.2 \mu \mathrm{mol} \cdot \mathrm{g}^{-1}$. The silica-supported molybdenum phosphide catalyst had much larger $\mathrm{CO}$ uptakes than the others, one order of magnitude larger than the nickel, cobalt and iron phosphide catalysts. The lowest dispersion was found for the $\mathrm{WP} / \mathrm{SiO}_{2}$ catalyst, which was one order of magnitude lower than that of the $\mathrm{Ni}$, Co and $\mathrm{Fe}$ phosphide catalysts. Thus, the order of dispersions obtained was: $\mathrm{MoP} / \mathrm{SiO}_{2}>>\mathrm{NiP} / \mathrm{SiO}_{2} \sim$ $\mathrm{CoP} / \mathrm{SiO}_{2} \sim \mathrm{FeP} / \mathrm{SiO}_{2}>>\mathrm{WP} / \mathrm{SiO}_{2}$.

The above results are consistent with the XRD results, which note that molybdenum phosphide must be very well-dispersed on the silica substrate. 
Since the metal mass contents were the same for all catalysts, the $\mathrm{W}$ atomic content was lower because of the larger W atomic weight, which would support the fact that this sample presents a lower amount of surface metal atoms (Table 2).

A greater dispersion for a silica-supported molybdenum phosphide catalyst compared to the other active phases was also found in literature [33]. However, the trend found for the other phases was not the same. It should be considered that the preparation method and the phosphorous precursor are different in both cases and may influence the achieved dispersion. In another work [31] that uses the same catalyst formulations and preparation method, the molybdenum phosphide catalyst also presents the highest dispersion. It should be mentioned that the low dispersion obtained for cobalt and nickel phosphide catalysts could be, in part, derived from the lower proportion of phosphorous, since in these catalysts the M/P stoichiometry was 2 instead of 1 . As reported in literature, a greater proportion of phosphorous seems to favor the dispersion of the metallic phase $[34,35]$.

The acidity of the reduced catalysts was determined by temperature programmed desorption of ammonia ( $\left.\mathrm{NH}_{3}-\mathrm{TPD}\right)$. The desorption profiles for all the reduced catalysts are displayed in Figure 3 , and the total amount of adsorbed $\mathrm{NH}_{3}$ are reported in Table 2. The TPD profiles show that all the catalysts present mostly weak and medium acid sites since the main desorption peak is centered approximately $443 \mathrm{~K}$. This desorption peak is related to two overlapped contributions: one centered around the previous value, ascribed to $\mathrm{POH}$ groups (which are terminal groups in phosphates generated by disproportional reaction of metal phosphite) or $\mathrm{MOH}$ groups, both with Brønsted 
acidity, and another, at some higher temperature, related to Lewis acid sites in metal particles with some positive character $\left(\mathrm{M}^{\delta+}\right)$, due to the electron transfer from the metal to the $P[31,36]$.

As reported in Table 2, the total acidity amount changes considerably for the catalysts, and follows the order: MoP $>$ WP $>\mathrm{NiP} \sim \mathrm{CoP}>\mathrm{FeP}$. In a previous contribution [36], authors also found that the most acidic sample $\left(\mathrm{MoP} / \mathrm{SiO}_{2}\right)$ presents the highest metal dispersion. The higher amount of acid sites on $\mathrm{MoP} / \mathrm{SiO}_{2}$ and $\mathrm{WP} / \mathrm{SiO}_{2}$ may be related to $\mathrm{Mo}-\mathrm{OH}$ and $\mathrm{W}-\mathrm{OH}$ groups formed during the reduction process [16]. This is because the Mo and W sites, which present a lower density of metal d states near the Fermi level, have a larger positive charge than Fe, Co and Ni sites in the phosphides [16, 37].

XPS spectra of reduced samples are compiled in Figure 4 and Table 3 lists the binding energies $(e V)$ of core electrons (Ni 2p $3 / 2$, Co $2 p$, Fe 2p, W 4f core levels) and the surface atomic ratios of the phosphide samples. The $P 2 p$ core-level present, for all the catalysts, two contributions of the $P 2 p_{3 / 2}$ component, a low binding energy (128.8-129.3 eV) peak attributed to $\mathrm{P}^{\delta-}$ species which are present in phosphides, and one at higher binding energy, approximately 133.5-134.1 eV, mainly assigned to phosphite species (unreduced $\mathrm{HPO}_{3} \mathrm{H}^{-}$species) from the precursor salt, at approximately 133.4 eV [25] and to phosphates, at approximately $134 \mathrm{eV}$, resulting from passivation $[38,39]$. In the case of the $\mathrm{NiP} / \mathrm{SiO}_{2}$ catalyst, this contribution is centered at higher binding energy (see Table 3), which is explained by a higher proportion of phosphates in this catalyst.

The Ni $2 p$ core-level spectrum presents two main contributions. The first one is centered at $850.7 \mathrm{eV}$, assigned to metallic nickel in phosphide structures. The 
second one is at approximately $856.3 \mathrm{eV}$, which is accompanied by a broad satellite signal at approximately $6.5 \mathrm{eV}$ higher energy, is attributed to $\mathrm{Ni}^{2+}$ in unreduced $\mathrm{PO}_{3}^{-} / \mathrm{PO}_{4}^{-}[19,25]$. Similarly, the Co $2 \mathrm{p}$ core-level spectrum also presents two main components, the one at lower binding energy $(777.5 \mathrm{eV})$ is ascribed to metallic cobalt in Co-P structures and the one centered at approximately $781 \mathrm{eV}$, along with a satellite placed at approximately $3.3 \mathrm{eV}$ higher energy, is assigned to $\mathrm{Co}^{2+}$ species [40].

The $\mathrm{Fe} 2 \mathrm{p}_{3 / 2}$ spectrum for the $\mathrm{FeP} / \mathrm{SiO}_{2}$ reduced catalyst presents two components. The first one is at $707.4 \mathrm{eV}$, close to the binding energy associated to metallic iron $(707 \mathrm{eV})$, and related to $\mathrm{Fe}-\mathrm{P}$ bonding structures ( $\mathrm{FeP}$ or $\mathrm{Fe}_{2} \mathrm{P}$ ), hence it is ascribed to $\mathrm{Fe}^{\delta+}$ in iron phosphide [41]. The second one, centered at approximately $711.2 \mathrm{eV}$, is assigned to the oxide layers of $\mathrm{Fe}_{2} \mathrm{O}_{3}$ at the surface [42].

XPS spectrum in the Mo $3 d$ region for the reduced catalyst $\mathrm{MoP} / \mathrm{SiO}_{2}$ shows the presence of molybdenum phases with different oxidation states. The Mo $3 d_{5 / 2}$ peak at $230.1 \mathrm{eV}$ is assigned to partially reduced molybdenum (Mo ${ }^{4+}$ species) and the peak centered at $232.5 \mathrm{eV}$ is typical of $\mathrm{Mo}^{6+}$ species [39]. A small contribution centered at ca. $228 \mathrm{eV}$, assigned at $\mathrm{Mo}^{\bar{\delta}}$ surface site forming MoP, cannot be discarded [38].

The $\mathrm{W} 4 \mathrm{f}$ spectrum for the $\mathrm{WP} / \mathrm{SiO}_{2}$ reduced catalyst presents two contributions (W4f $f_{7 / 2}$ and $W 4 f_{5 / 2}$ ), each one in the form of doublets. The first peak of the doublet in the $\mathrm{W}_{4} \mathrm{f}_{7 / 2}$ component is located at ca. $32.6 \mathrm{eV}$ and is ascribed to $\mathrm{W}^{4+}$ species and the second one, located at approximately $36.3 \mathrm{eV}$, is assigned to $\mathrm{W}^{6+}$ species [19]. In this catalyst, species assigned to tungsten phosphide $\left(\mathrm{W}^{\delta+}\right.$ or $\mathrm{W}^{0}$ ), at ca. $31.2 \mathrm{eV}$, are not clearly observed, although they cannot be 
excluded, since the signal could be overlapped with the one corresponding to the peak centered at $32.6 \mathrm{eV}$.

Thus, from above results, it can be concluded that the surface of the samples is only partially reduced to the phosphide. The relative proportion of the different, more or less reduced phases in each catalyst is depicted, in parentheses, in Table 3. From these data, it can be concluded that the phosphide nickel catalyst is the one that presents a greater surface proportion of phosphide.

From the XPS results, it is revealed that both the metal and phosphorous dispersions greatly depend on the transition metal type. The surface atomic ratios of $\mathrm{M} / \mathrm{Si}$ show the following trend $\left(\mathrm{CoP} / \mathrm{SiO}_{2}>\mathrm{NiP} / \mathrm{SiO}_{2}>\mathrm{MoP} / \mathrm{SiO}_{2}>\right.$ $\mathrm{FeP} / \mathrm{SiO}_{2}>\mathrm{WP} / \mathrm{SiO}_{2}$ ). However, considering that the prepared catalysts present the same amount in weight of metal, $15 \%$ weight, but the atomic weight differs among them, in order to compare the phosphide dispersion achieved for each sample, the ratio $(\mathrm{M} / \mathrm{Si}) \times \mathrm{ps} /(\mathrm{M} / \mathrm{Si})$ nominal has been calculated and the obtained values are reported in Table 3. In this case, we found the trend: MoP > $\mathrm{CoP}>\mathrm{NiP}>\mathrm{WP}>\mathrm{FeP}$, which support the fact that molybdenum phase achieves a greater dispersion.

Considering that the nominal ratio $\mathrm{M} / \mathrm{P}$ is 2 for the $\mathrm{Ni}$ and $\mathrm{Co}$ phosphide catalysts and 1 for the others, a surface enrichment of $P$ in the nickel, tungsten and also, but to a lesser extent, in the molybdenum catalyst should be noted. However, the cobalt catalyst presents a surface enrichment in metal. In the case of the iron catalyst, the surface metal/phosphorous ratio is similar to the nominal one. 


\subsection{Catalytic Activity Tests}

All the prepared catalysts were tested in the hydrotreatment of methyl laurate. We present the activity data once the steady state was reached, that is after 2-3 $\mathrm{h}$ of reaction. After then, obtained activity data are quite stable, and reported conversions and selectivities are average values between 3 to $6 \mathrm{~h}$ on stream. All the catalysts were active in the above reaction (Table 4), but the conversion depends on the type of metal phosphide employed. The most active is the MoPbased catalyst, and the catalytic activity order found was the following: $\mathrm{MoP} / \mathrm{SiO}_{2}>\mathrm{CoP} / \mathrm{SiO}_{2}>\mathrm{NiP} / \mathrm{SiO}_{2}>>\mathrm{WP} / \mathrm{SiO}_{2} \approx \mathrm{FeP} / \mathrm{SiO}_{2}$. The better catalytic performance of MoP can be attributed to its higher active phase dispersion as shown by the XRD, XPS and CO chemisorption analyses. In addition, this catalyst also shows a high number of acid sites (as shown in the ammonia desorption profiles), which promotes the deoxygenation reaction [43]. As can be derived from the acidity analyses, as previously commented, the origin of this greater acidity for $\mathrm{MoP} / \mathrm{SiO}_{2}$ is also ascribed to the larger dispersion of the phosphide in this catalyst.

Hydrocarbons are the main product for all tested catalysts, but we detect the presence of oxygenates (mainly lauric acid and lauryl alcohol) in the catalysts with low conversion level $\left(\mathrm{WP} / \mathrm{SiO}_{2}\right.$ and $\left.\mathrm{FeP} / \mathrm{SiO}_{2}\right)$. We also detect differences in the distribution of $\mathrm{C}_{12}$ and $\mathrm{C}_{11}$ hydrocarbons. Catalysts based on phosphide of light metals (CoP, NiP and $\mathrm{FeP}$ ) produce more $\mathrm{C}_{11}$ hydrocarbons, while the phosphides of heavier metals (MoP and WP) produce more $\mathrm{C}_{12}$ hydrocarbons. Thus, it seems that hydrodeoxygenation follows different pathways depending on the catalyst used. On MoP and WP, the main route is hydrogenation while on $\mathrm{CoP}, \mathrm{NiP}$ and $\mathrm{FeP}$ the main route is decarboxylation/decarbonylation. 
In order to know the activity per surface metal atom, we have calculated turnover frequencies based on converted molecules of methyl laurate at steady state and metal dispersions. TOF values shows that the intrinsic activity follows the following trend: $\mathrm{WP}>\mathrm{CoP}>\mathrm{NiP}>\mathrm{FeP}>\mathrm{MoP}$ (Table 4). These results indicated that not only the dispersion affects the catalytic activity, but also the intrinsic activity of the metal phosphide has an effect, an encourage us to try a method to increase the low metal dispersion achieved, with most of the transition metal phosphides, using this synthesis method.

The reaction conditions were optimized using the MoP catalyst, the most active and selective for methyl laurate $\mathrm{HDO}$, modifying total pressure, reaction temperature and liquid flow. The reaction results show that an increase in the reaction temperature from 553 to $593 \mathrm{~K}$ produces an increase in the methyl laurate conversion (entries 1 to 3 of Table 5) and some changes in the selectivity to the hydrocarbons produced. The selectivity to $\mathrm{C}_{6}-\mathrm{C}_{10}$ hydrocarbons increases slightly with the temperature because a higher reaction temperature favors cracking side reactions. On the other hand, the $\mathrm{C}_{12} / \mathrm{C}_{11}$ ratio decreases when the reaction temperature increases, indicating that higher temperatures may favor the decarboxylation/decarbonylation route.

The total pressure also affects the reaction results, so that an increase in the total pressure increases the conversion of methyl laurate (entries 1, 4 and 5 of Table 5), this effect being more evident when the pressure changes from 1.0 $\mathrm{MPa}$ to 2.0 MPa than when it increases from 2.0 MPa to 3.0 MPa. The increase in the conversion could be related to increasing pressure favoring the adsorption of hydrogen on the catalyst surface, which increases the reaction rate. Nevertheless, an increase in the hydrogen pressure over 2.0 MPa do not 
produce an enhancement in the conversion of methyl laurate. The increase in pressure also increases the $\mathrm{C}_{12} / \mathrm{C}_{11}$ ratio. This effect is the expected because an increase in the adsorbed hydrogen on the catalyst surface favors the hydrogenation route $\left(\mathrm{C}_{12}\right.$ production $)$ against the decarboxylation/decarbonylation route ( $\mathrm{C}_{11}$ production). The selectivity to hydrocarbons of $\mathrm{C}_{6}-\mathrm{C}_{10}$ does not change with pressure, because hydrogen pressure does not play a main role in the cracking reactions.

The change in the liquid flow (liquid residence time) also affects the reaction results. An increase in the total pressure decreases the conversion of methyl laurate (entries 1, 6 and 7 of Table 5) because a high liquid flow implies a low contact time of the liquid with the catalyst. The selectivity of the products is also affected by the liquid flow (contact time of the liquid). At high flow (short contact time), the main products are hydrocarbons, mainly $\mathrm{C}_{12}$. We also identify the presence of some oxygenates (mainly lauryl alcohol). In contrast, a decrease in the liquid flow yields to the detection of only hydrocarbons, but the selectivity to short-chain hydrocarbons $\left(\mathrm{C}_{6}-\mathrm{C}_{10}\right)$ is higher. This higher formation of shortchain hydrocarbons is due to the increase in contact time favoring cracking reactions. The combination of both effects produces a maximum in the $\mathrm{C}_{12}$ hydrocarbons selectivity for a liquid flow of $0.3 \mathrm{~mL} \cdot \mathrm{min}^{-1}$.

Based on the previous study, we have considered that the optimal results can be obtained under the following conditions: $573 \mathrm{~K}, 2.0 \mathrm{MPa}$, liquid flow 0.3 $\mathrm{mL} \cdot \mathrm{min}^{-1}$. A higher pressure can also be attractive, but the increase in the pressure to $3.0 \mathrm{MPa}$ implies an increase in the operation expenditure that is not compensated by an increase of hydrocarbon yield. Once the reaction conditions were optimized, we decided to study the stability of the most active catalyst, 
$\mathrm{MoP} / \mathrm{SiO}_{2}$, during a longer reaction time $(96 \mathrm{~h})$. The reaction results indicate that the values of conversion of methyl laurate, selectivity to $C_{12}$ hydrocarbons and $\mathrm{C}_{11}$ hydrocarbons $(85.9 \%, 94.2 \%$ and $4.1 \%$, respectively) are practically constant (Figure 5) without any sign of deactivation in the whole time of the experiments.

\section{Conclusions}

All catalysts prepared were active in the hydrotreatment of methyl laurate, showing the following order: MoP $>\mathrm{WP}>\mathrm{NiP} \approx \mathrm{CoP}>\mathrm{FeP}$. Hydrocarbons are the main products for all the catalysts, with mostly $\mathrm{C}_{12}$ being produced for MoP and $\mathrm{WP}$ and $\mathrm{C}_{11}$ for $\mathrm{CoP}, \mathrm{NiP}$ and $\mathrm{FeP}$, which indicates that hydrodeoxygenation follows different pathways depending on the catalyst used. Thus, on MoP and WP, the main route is hydrogenation, while on CoP, NiP and $\mathrm{FeP}$, it is decarboxylation/decarbonylation. The better catalytic performance of MoP is related to a higher active phase dispersion as shown by XRD, XPS and CO chemisorption analyses and to its greater acidity (as shown in the ammonia desorption profiles), which promotes the deoxygenation reaction.

The reaction conditions were optimized using the MoP catalyst, the most active and selective for methyl laurate hydrotreating, modifying the total pressure, reaction temperature and liquid residence time. The optimal results were obtained under the following conditions: $573 \mathrm{~K}, 2.0 \mathrm{MPa}$, and a liquid flow 0.1 $\mathrm{mL} \cdot \mathrm{min}^{-1} \cdot \mathrm{g}^{-1}$ catalyst, which corresponds to $0.3 \mathrm{~mL} \cdot \mathrm{min}^{-1}$ for $3 \mathrm{~g}$ of catalyst used in our experiments. Under these reaction conditions, no deactivation was observed after $96 \mathrm{~h}$ during a durability test carried out with the catalyst based on MoP. 


\section{Acknowledgments}

This work was supported by the Spanish Ministry of Economy and Competitiveness (MINECO) through projects: ENE2013-47826-C4-2-R and ENE2016-74889-C4-3-R

\section{References}

[1] E. Corporan, T. Edwards, L. Shafer, M.J. DeWitt, C. Klingshirn, S. Zabarnick, Z. West, R. Striebich, J. Graham, J. Klein, Chemical, thermal stability, seal swell, and emissions studies of alternative jet fuels, Energy \& fuels, 25 (2011) 955-966.

[2] G. Knothe, Biodiesel and renewable diesel: A comparison, Progress in Energy and Combustion Science, 36 (2010) 364-373.

[3] R. Gough, T. Bruno, Comparison of alternative diesel fuels with the composition-explicit distillation curve method, Energy \& Fuels, 26 (2012) 69056913.

[4] S. Morales-Delarosa, J.M. Campos-Martin, Catalytic processes and catalyst development in biorefining, Advances in Biorefineries: Biomass and Waste Supply Chain Exploitation, Elsevier Ltd., 2014, pp. 152-198.

[5] M. Krár, S. Kovács, D. Kalló, J. Hancsók, Fuel purpose hydrotreating of sunflower oil on CoMo/Al 2 O 3 catalyst, Bioresource technology, 101 (2010) 9287-9293.

[6] D. Kubička, J. Horáček, M. Setnička, R. Bulánek, A. Zukal, I. Kubičková, Effect of support-active phase interactions on the catalyst activity and selectivity in deoxygenation of triglycerides, Applied Catalysis B: Environmental, 145 (2014) 101-107.

[7] D. Kubička, L. Kaluža, Deoxygenation of vegetable oils over sulfided Ni, Mo and NiMo catalysts, Applied Catalysis A: General, 372 (2010) 199-208.

[8] G.W. Huber, P. O'Connor, A. Corma, Processing biomass in conventional oil refineries: production of high quality diesel by hydrotreating vegetable oils in heavy vacuum oil mixtures, Applied Catalysis A: General, 329 (2007) 120-129.

[9] R. Sotelo-Boyás, Y. Liu, T. Minowa, Renewable Diesel Production from the Hydrotreating of Rapeseed Oil with Pt/Zeolite and NiMo/Al2O3Catalysts, Industrial \& Engineering Chemistry Research, 50 (2011) 2791-2799.

[10] K. Murata, Y. Liu, M. Inaba, I. Takahara, Production of Synthetic Diesel by Hydrotreatment of Jatropha Oils Using Pt-Re/H-ZSM-5 Catalyst, Energy \& Fuels, 24 (2010) 2404-2409.

[11] S. Bezergianni, A. Dimitriadis, A. Kalogianni, K.G. Knudsen, Toward hydrotreating of waste cooking oil for biodiesel production. Effect of pressure, 
H2/oil ratio, and liquid hourly space velocity, Industrial \& Engineering Chemistry Research, 50 (2011) 3874-3879.

[12] I. Kubičková, M. Snåre, K. Eränen, P. Mäki-Arvela, D.Y. Murzin, Hydrocarbons for diesel fuel via decarboxylation of vegetable oils, Catalysis Today, 106 (2005) 197-200.

[13] J.C. Serrano-Ruiz, E.V. Ramos-Fernandez, A. Sepulveda-Escribano, From biodiesel and bioethanol to liquid hydrocarbon fuels: new hydrotreating and advanced microbial technologies, Energy \& Environmental Science, 5 (2012) 5638-5652.

[14] C. Perego, M. Ricci, Diesel fuel from biomass, Catalysis Science \& Technology, 2 (2012) 1776-1786.

[15] S.T. Oyama, T. Gott, H. Zhao, Y.-K. Lee, Transition metal phosphide hydroprocessing catalysts: A review, Catalysis Today, 143 (2009) 94-107.

[16] J. Chen, H. Shi, L. Li, K. Li, Deoxygenation of methyl laurate as a model compound to hydrocarbons on transition metal phosphide catalysts, Applied Catalysis B: Environmental, 144 (2014) 870-884.

[17] Y. Yang, C. Ochoa-Hernández, V.A. de la Peña O'Shea, J.M. Coronado, D.P. Serrano, Ni2P/SBA-15 As a Hydrodeoxygenation Catalyst with Enhanced Selectivity for the Conversion of Methyl Oleate Inton-Octadecane, ACS Catalysis, 2 (2012) 592-598.

[18] Y. Yang, J. Chen, H. Shi, Deoxygenation of Methyl Laurate as a Model Compound to Hydrocarbons on Ni2P/SiO2, Ni2P/MCM-41, and Ni2P/SBA-15 Catalysts with Different Dispersions, Energy \& Fuels, 27 (2013) 3400-3409.

[19] P. Bui, J.A. Cecilia, S.T. Oyama, A. Takagaki, A. Infantes-Molina, H. Zhao, D. Li, E. Rodríguez-Castellón, A. Jiménez López, Studies of the synthesis of transition metal phosphides and their activity in the hydrodeoxygenation of a biofuel model compound, Journal of Catalysis, 294 (2012) 184-198.

[20] Q. Guan, W. Li, M. Zhang, K. Tao, Alternative synthesis of bulk and supported nickel phosphide from the thermal decomposition of hypophosphites, Journal of Catalysis, 263 (2009) 1-3.

[21] G. Shi, J. Shen, New synthesis method for nickel phosphide nanoparticles: solid phase reaction of nickel cations with hypophosphites, Journal of Materials Chemistry, 19 (2009) 2295-2297.

[22] T.I. Korányi, Z. Vít, D.G. Poduval, R. Ryoo, H.S. Kim, E.J. Hensen, SBA15-supported nickel phosphide hydrotreating catalysts, Journal of Catalysis, 253 (2008) 119-131.

[23] A. Wang, Y. Wang, T. Kabe, Y. Chen, A. Ishihara, W. Qian, Hydrodesulfurization of dibenzothiophene over siliceous MCM-41-supported catalysts: I. Sulfided Co-Mo catalysts, Journal of Catalysis, 199 (2001) 19-29.

[24] Y. Yang, C. Ochoa-Hernández, P. Pizarro, V.A. de la Peña O'Shea, J.M. Coronado, D.P. Serrano, Influence of the Ni/P ratio and metal loading on the performance of NixPy/SBA-15 catalysts for the hydrodeoxygenation of methyl oleate, Fuel, 144 (2015) 60-70. 
[25] J.A. Cecilia, A. Infantes-Molina, E. Rodríguez-Castellón, A. Jiménez-López, A novel method for preparing an active nickel phosphide catalyst for HDS of dibenzothiophene, Journal of Catalysis, 263 (2009) 4-15.

[26] P. Burattin, M. Che, C. Louis, Ni/SiO2 materials prepared by depositionprecipitation: influence of the reduction conditions and mechanism of formation of metal particles, The Journal of Physical Chemistry B, 104 (2000) 1048210489.

[27] C. Wagner, L. Davis, M. Zeller, J. Taylor, R. Raymond, L. Gale, Empirical atomic sensitivity factors for quantitative analysis by electron spectroscopy for chemical analysis, Surface and Interface Analysis, 3 (1981) 211-225.

[28] M. Thommes, K. Kaneko, A.V. Neimark, James P. Olivier, F. RodriguezReinoso, J. Rouquerol, K.S.W. Sing, Physisorption of gases, with special reference to the evaluation of surface area and pore size distribution (IUPAC Technical Report), Pure and Applied Chemistry, 87 (2015) 1051-1069.

[29] K.S.W. Sing, D.H. Everett, R.A.W. Haul, L. Moscou, R.A. Pierotti, J. Rouquerol, T. Siemieniewska, Reporting physisorption data for gas/solid systems with special reference to the determination of surface area and porosity, Pure and Applied Chemistry, 57 (1985) 603-619.

[30] C.-B. Wang, R.G. Herman, C. Shi, Q. Sun, J.E. Roberts, V2O5-SiO2 xerogels for methane oxidation to oxygenates: preparation, characterization, and catalytic properties, Applied Catalysis A: General, 247 (2003) 321-333.

[31] K. Li, R. Wang, J. Chen, Hydrodeoxygenation of Anisole over SilicaSupported Ni2P, MoP, and NiMoP Catalysts, Energy \& Fuels, 25 (2011) 854863.

[32] P. Clark, X. Wang, S.T. Oyama, Characterization of Silica-Supported Molybdenum and Tungsten Phosphide Hydroprocessing Catalysts by 31P Nuclear Magnetic Resonance Spectroscopy, Journal of Catalysis, 207 (2002) 256-265.

[33] H. Zhao, D. Li, P. Bui, S. Oyama, Hydrodeoxygenation of guaiacol as model compound for pyrolysis oil on transition metal phosphide hydroprocessing catalysts, Applied Catalysis A: General, 391 (2011) 305-310.

[34] J.A. Cecilia, A. Infantes-Molina, E. Rodríguez-Castellón, A. Jiménez-López, S.T. Oyama, Oxygen-removal of dibenzofuran as a model compound in biomass derived bio-oil on nickel phosphide catalysts: Role of phosphorus, Applied Catalysis B: Environmental, 136-137 (2013) 140-149.

[35] S. Oyama, X. Wang, Y.-K. Lee, K. Bando, F. Requejo, Effect of phosphorus content in nickel phosphide catalysts studied by XAFS and other techniques, Journal of catalysis, 210 (2002) 207-217.

[36] Z. Pan, R. Wang, M. Li, Y. Chu, J. Chen, Deoxygenation of methyl laurate to hydrocarbons on silica-supported Ni-Mo phosphides: Effect of calcination temperatures of precursor, Journal of Energy Chemistry, 24 (2015) 77-86.

[37] A. Benadda, A. Katrib, A. Barama, Hydroisomerization of $n$-heptane and dehydration of 2-propanol on $\mathrm{MoO} 2(\mathrm{H} \mathrm{x})$ ac. catalysts, Applied Catalysis A: General, 251 (2003) 93-105. 
[38] A. Infantes-Molina, C. Moreno-León, B. Pawelec, J. Fierro, E. RodríguezCastellón, A. Jiménez-López, Simultaneous hydrodesulfurization and hydrodenitrogenation on MoP/SiO 2 catalysts: Effect of catalyst preparation method, Applied Catalysis B: Environmental, 113 (2012) 87-99.

[39] D.C. Phillips, S.J. Sawhill, R. Self, M.E. Bussell, Synthesis, Characterization, and Hydrodesulfurization Properties of Silica-Supported Molybdenum Phosphide Catalysts, Journal of Catalysis, 207 (2002) 266-273.

[40] A. Infantes-Molina, E. Gralberg, J.A. Cecilia, E. Finocchio, E. RodríguezCastellón, Nickel and cobalt phosphides as effective catalysts for oxygen removal of dibenzofuran: role of contact time, hydrogen pressure and hydrogen/feed molar ratio, Catal. Sci. Technol., 5 (2015) 3403-3415.

[41] F. Luo, H.-L. Su, W. Song, Z.-M. Wang, Z.-G. Yan, C.-H. Yan, Magnetic and magnetotransport properties of $\mathrm{Fe} 2 \mathrm{P}$ nanocrystallites via a solvothermal route, Journal of Materials Chemistry, 14 (2004) 111-115.

[42] C.Y. Son, I.H. Kwak, Y.R. Lim, J. Park, FeP and FeP 2 nanowires for efficient electrocatalytic hydrogen evolution reaction, Chemical Communications, 52 (2016) 2819-2822.

[43] L. Wang, H. Wan, S. Jin, X. Chen, C. Li, C. Liang, Hydrodeoxygenation of dibenzofuran over $\mathrm{SiO} 2, \mathrm{Al} 2 \mathrm{O} / \mathrm{SiO} 2 \mathrm{and} \mathrm{ZrO} 2 / \mathrm{SiO} 2$ supported $\mathrm{Pt}$ catalysts, Catal. Sci. Technol., 5 (2015) 465-474. 
Table 1 Textural properties of the support and reduced catalysts

\begin{tabular}{|c|c|c|c|}
\hline & $\begin{array}{c}\text { BET surface area } \\
\left(\mathbf{m}^{2} \cdot \mathbf{g}^{-1}\right)\end{array}$ & $\begin{array}{c}\text { Pore volume } \\
\left(\mathbf{m L} \cdot \mathbf{g}^{-1}\right)\end{array}$ & $\begin{array}{c}\text { Average pore } \\
\text { diameter } \\
(\mathbf{n m})\end{array}$ \\
\hline Support $\left(\mathrm{SiO}_{2}\right)$ & 241 & 0.90 & 11.7 \\
\hline $\mathrm{NiP} / \mathrm{SiO}_{2}$ & 165 & 0.62 & 11.5 \\
\hline $\mathrm{CoP} / \mathrm{SiO}_{2}$ & 129 & 0.60 & 12.0 \\
\hline $\mathrm{FeP} / \mathrm{SiO}_{2}$ & 119 & 0.59 & 11.8 \\
\hline $\mathrm{MoP} / \mathrm{SiO}_{2}$ & 150 & 0.53 & 11.6 \\
\hline $\mathrm{WP} / \mathrm{SiO}_{2}$ & 182 & 0.71 & 11.7 \\
\hline
\end{tabular}


Table 2 Metal dispersions, structural and acidic properties of the reduced/passivated catalysts

\begin{tabular}{|c|c|c|c|c|c|c|c|}
\hline Catalyst & $\begin{array}{l}\text { Crystal } \\
\text {. phase }\end{array}$ & PDF card & $2 \theta\left(^{\circ}\right)$ & $\begin{array}{l}\text { Crystallite } \\
\text { size (nm) }\end{array}$ & $\begin{array}{c}\text { surface } \\
\text { metal atoms } \\
(\mu \mathrm{moles} / \mathrm{g})\end{array}$ & D (\%) & $\begin{array}{c}\text { Total acidity } \\
\left(\mathbf{m m o l}^{2}\right. \\
\left.\mathrm{NH}_{3} / \mathbf{g}\right)\end{array}$ \\
\hline \multirow{2}{*}{$\mathrm{NiP} / \mathrm{SiO}_{2}$} & $\mathrm{Ni}_{2} \mathrm{P}$ & 01-074-1385 & 40.8 & 30.7 & \multirow{2}{*}{18.7} & \multirow{2}{*}{0.73} & \multirow{2}{*}{0.082} \\
\hline & $\mathrm{Ni}_{2} \mathrm{H}$ & 01-083-2378 & 41.7 & 38.0 & & & \\
\hline $\mathrm{CoP} / \mathrm{SiO}_{2}$ & CoP & 00-029-0497 & 46.2 & 5.6 & 15.2 & 0.60 & 0.081 \\
\hline \multirow{2}{*}{$\mathrm{FeP} / \mathrm{SiO}_{2}$} & $\mathrm{FeP}$ & $00-078-1443$ & 48.4 & 24.3 & \multirow{2}{*}{12.7} & \multirow{2}{*}{0.47} & \multirow{2}{*}{0.039} \\
\hline & $\mathrm{Fe}_{2} \mathrm{P}$ & $00-01-1200$ & 40.4 & 20.7 & & & \\
\hline $\mathrm{MoP} / \mathrm{SiO}_{2}$ & \multicolumn{4}{|c|}{ not detected } & 114.2 & 7.30 & 0.242 \\
\hline $\mathrm{WP} / \mathrm{SiO}_{2}$ & WP & $00-029-1364$ & 31.0 & 14.4 & 0.2 & 0.02 & 0.130 \\
\hline
\end{tabular}


Table 3 Binding energies and surface atomic ratios (XPS) for the reduced catalysts

\begin{tabular}{|c|c|c|c|c|c|c|}
\hline Catalyst & P 2p & Metal & $\begin{array}{c}\mathrm{M} / \mathrm{Si} \\
\text { at }\end{array}$ & $\begin{array}{c}\mathbf{P} / \mathbf{S i} \\
\text { at }\end{array}$ & $\begin{array}{c}M / P \\
\text { at }\end{array}$ & $\begin{array}{l}(\mathrm{M} / \mathrm{Si})_{\mathrm{XPS}} / \\
(\mathrm{M} / \mathrm{Si})_{\text {nom }}\end{array}$ \\
\hline $\mathrm{NiP} / \mathrm{SiO}_{2}$ & $\begin{array}{l}128.8 \\
134.4\end{array}$ & $\begin{array}{l}850.7(66) \\
856.3(34)\end{array}$ & 0.040 & 0.068 & 0.588 & 0.212 \\
\hline $\mathrm{CoP} / \mathrm{SiO}_{2}$ & $\begin{array}{l}128.8 \\
133.3\end{array}$ & $\begin{array}{l}777.5(41) \\
781.0(59)\end{array}$ & 0.048 & 0.015 & 3.200 & 0.242 \\
\hline $\mathrm{FeP} / \mathrm{SiO}_{2}$ & $\begin{array}{l}128.8 \\
133.4\end{array}$ & $\begin{array}{l}707.4(22) \\
711.2(78)\end{array}$ & 0.015 & 0.014 & 1.071 & 0.071 \\
\hline $\mathrm{MoP} / \mathrm{SiO}_{2}$ & $\begin{array}{l}128.8 \\
134.1\end{array}$ & $\begin{array}{l}230.1(22) \\
232.5(78)\end{array}$ & 0.031 & 0.037 & 0.838 & 0.265 \\
\hline $\mathrm{WP} / \mathrm{SiO}_{2}$ & $\begin{array}{l}128.8 \\
134.0\end{array}$ & $\begin{array}{l}32.6(24) \\
35.9(76)\end{array}$ & 0.012 & 0.021 & 0.571 & 0.203 \\
\hline
\end{tabular}


Table 4 Catalytic activity results at steady state for the different catalysts prepared. Reaction conditions: $\mathrm{T}=573 \mathrm{~K}$, catalyst $=3 \mathrm{~g}$, Liquid Flow $=0.3 \mathrm{~mL} \cdot \mathrm{min}^{-1}, \mathrm{P}=2.0 \mathrm{MPa}, \mathrm{H}_{2} /$ liquid $(\mathrm{mol})=300$.

\begin{tabular}{|c|c|c|c|c|c|c|c|c|}
\hline \multirow{2}{*}{ Catalyst } & \multirow{2}{*}{$\begin{array}{l}\text { Methyl Laurate } \\
\text { Conversion (\%) }\end{array}$} & \multicolumn{4}{|c|}{ Selectivity to } & \multirow{2}{*}{$\begin{array}{c}\mathrm{C}_{12} / \mathrm{C}_{11} \\
(\mathrm{~mol} / \mathrm{mol})\end{array}$} & \multirow{2}{*}{$\begin{array}{c}\mathrm{CH}_{4} / \mathrm{CO} \\
(\mathrm{mol} / \mathrm{mol})\end{array}$} & \multirow{2}{*}{$\begin{array}{c}\operatorname{TOF}^{\star \star} \\
\left(\mathbf{s}^{-1}\right)\end{array}$} \\
\hline & & $\mathrm{HC} \mathrm{C}_{12}(\%)$ & $\mathrm{HC} \mathrm{C}_{11}(\%)$ & $\mathrm{HC} \mathrm{C}_{6}-\mathrm{C}_{10}(\%)$ & Others $^{\star}(\%)$ & & & \\
\hline $\mathrm{NiP} / \mathrm{SiO}_{2}$ & 71.9 & 17.3 & 72.3 & 8.7 & 0.8 & 0.24 & 0.4 & 0.26 \\
\hline $\mathrm{CoP} / \mathrm{SiO}_{2}$ & 77.6 & 12.4 & 76.3 & 9.8 & 0.5 & 0.16 & 0.3 & 0.35 \\
\hline $\mathrm{FeP} / \mathrm{SiO}_{2}$ & 18.6 & 9.0 & 27.3 & -- & 17.2 & 0.33 & 0.8 & 0.10 \\
\hline $\mathrm{MoP} / \mathrm{SiO}_{2}$ & 86.0 & 94.5 & 4.2 & 0.8 & 0.5 & 22.50 & 5.0 & 0.05 \\
\hline $\mathrm{WP} / \mathrm{SiO}_{2}$ & 22.5 & 25.5 & 4.4 & -- & 16.5 & 5.80 & 4.3 & 7.61 \\
\hline
\end{tabular}

${ }^{*}$ Others: mainly lauric acid and lauryl alcohol.

**Transformed methyl laurate molecules/surface metal atom and second 
Table 5 Study of the reaction conditions with catalyst $\mathrm{MoP} / \mathrm{SiO}_{2}$

\begin{tabular}{|c|c|c|c|c|c|c|c|}
\hline \multirow{2}{*}{$\mathrm{T}(\mathrm{K})$} & \multirow{2}{*}{$\mathrm{P}$ (MPa) } & \multirow{2}{*}{$\begin{array}{l}\text { Liquid Flow } \\
\left(\mathrm{ml}^{\mathrm{min}} \mathrm{min}^{-1}\right)\end{array}$} & \multirow{2}{*}{$\begin{array}{l}\text { Methyl Laurate } \\
\text { Conversion (\%) }\end{array}$} & \multirow[b]{2}{*}{$\mathrm{HC} \mathrm{C}_{12}(\%)$} & \multirow[b]{2}{*}{$\mathrm{HC} \mathrm{C}_{11}(\%)$} & \multirow[b]{2}{*}{$\mathrm{HC} \mathrm{C}_{6}-\mathrm{C}_{10}(\%)$} & \multirow[b]{2}{*}{$\begin{array}{c}\mathrm{C}_{12} / \mathrm{C}_{11} \\
(\mathrm{~mol} / \mathrm{mol})\end{array}$} \\
\hline & & & & & & & \\
\hline 573 & 2.0 & 0.3 & 86.0 & 94.5 & 4.2 & 1.3 & 22.5 \\
\hline 553 & 2.0 & 0.3 & 51.0 & 83.0 & 3.2 & 0.5 & 25.9 \\
\hline 593 & 2.0 & 0.3 & 97.0 & 86.4 & 5.8 & 7.8 & 15.0 \\
\hline 573 & 1.0 & 0.3 & 63.8 & 88.9 & 7.3 & 0.6 & 12.1 \\
\hline 573 & 3.0 & 0.3 & 89.8 & 94.8 & 3.2 & 2.0 & 29.2 \\
\hline 573 & 2.0 & 0.2 & 97.2 & 83.5 & 3.8 & 12.7 & 21.7 \\
\hline 573 & 2.0 & 0.4 & 71.8 & 86.1 & 4.3 & 1.0 & 20.1 \\
\hline
\end{tabular}

Other reaction conditions: catalyst weight $=3 \mathrm{~g}, \mathrm{H}_{2} /$ liquid $(\mathrm{mol})=300$. 


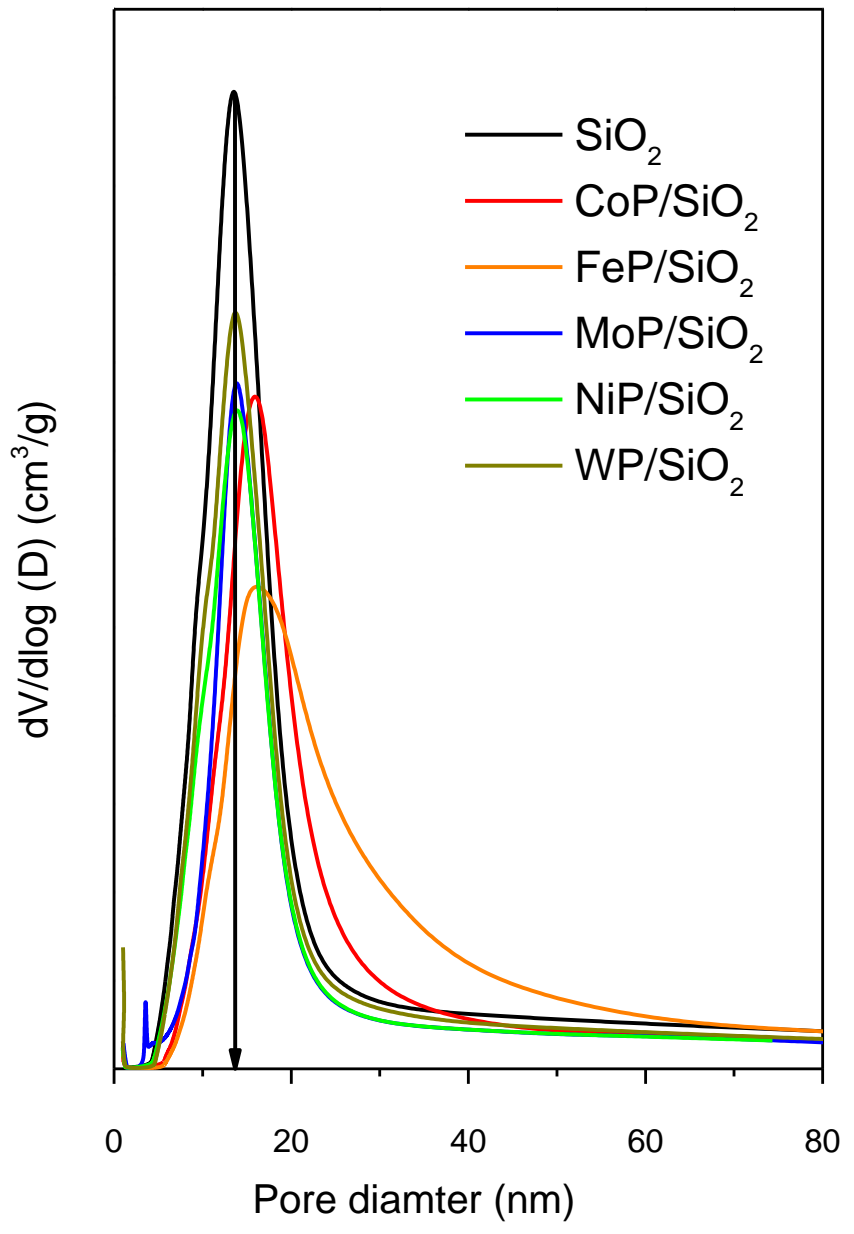

Figure 1 Pore distribution of catalysts and the starting silica obtained by applying the $\mathrm{BJH}$ method to the desorption branch of nitrogen adsorption isotherms at $77 \mathrm{~K}$. 


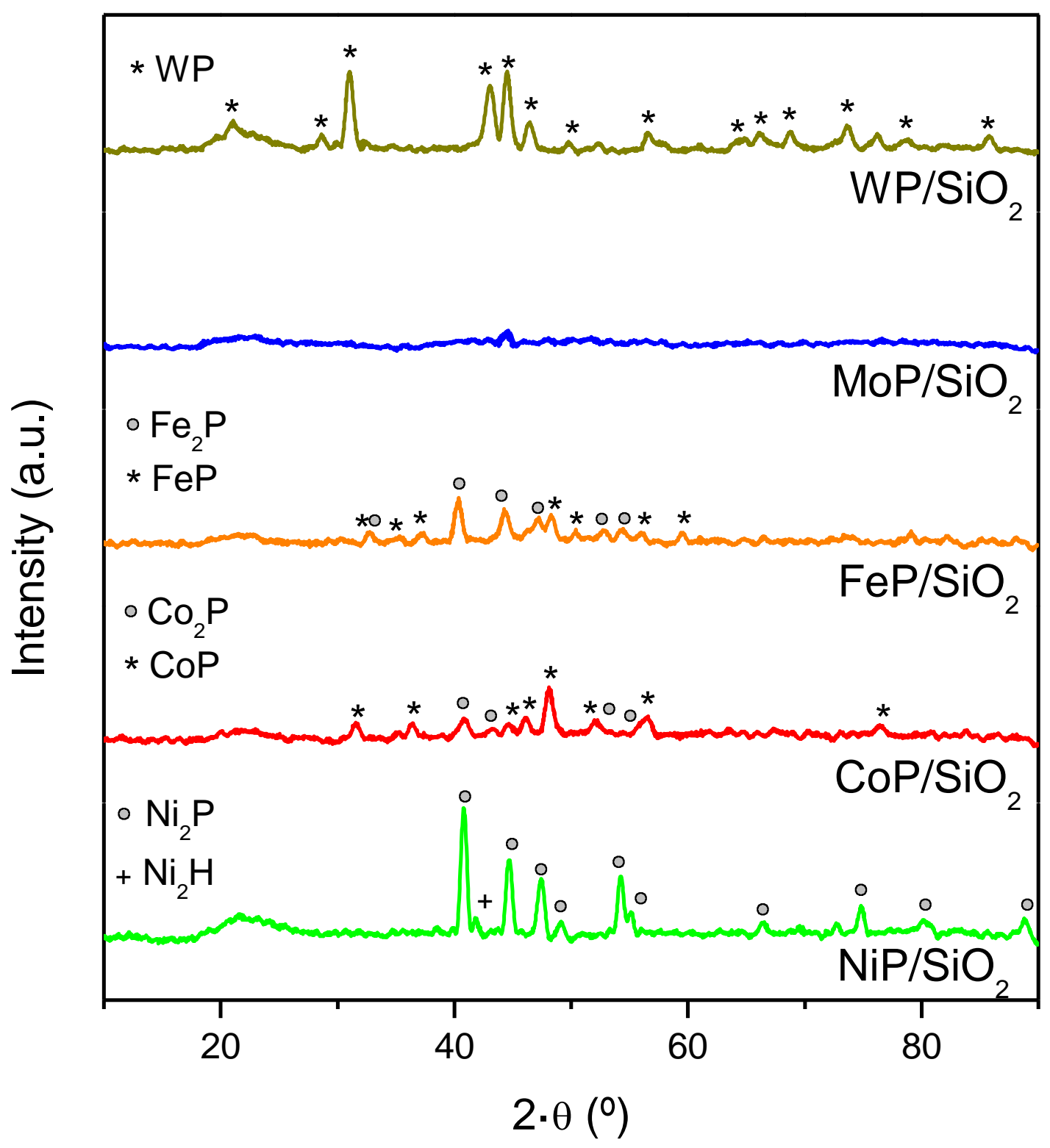

Figure 2 XRD patterns of the reduced/passivated catalysts 


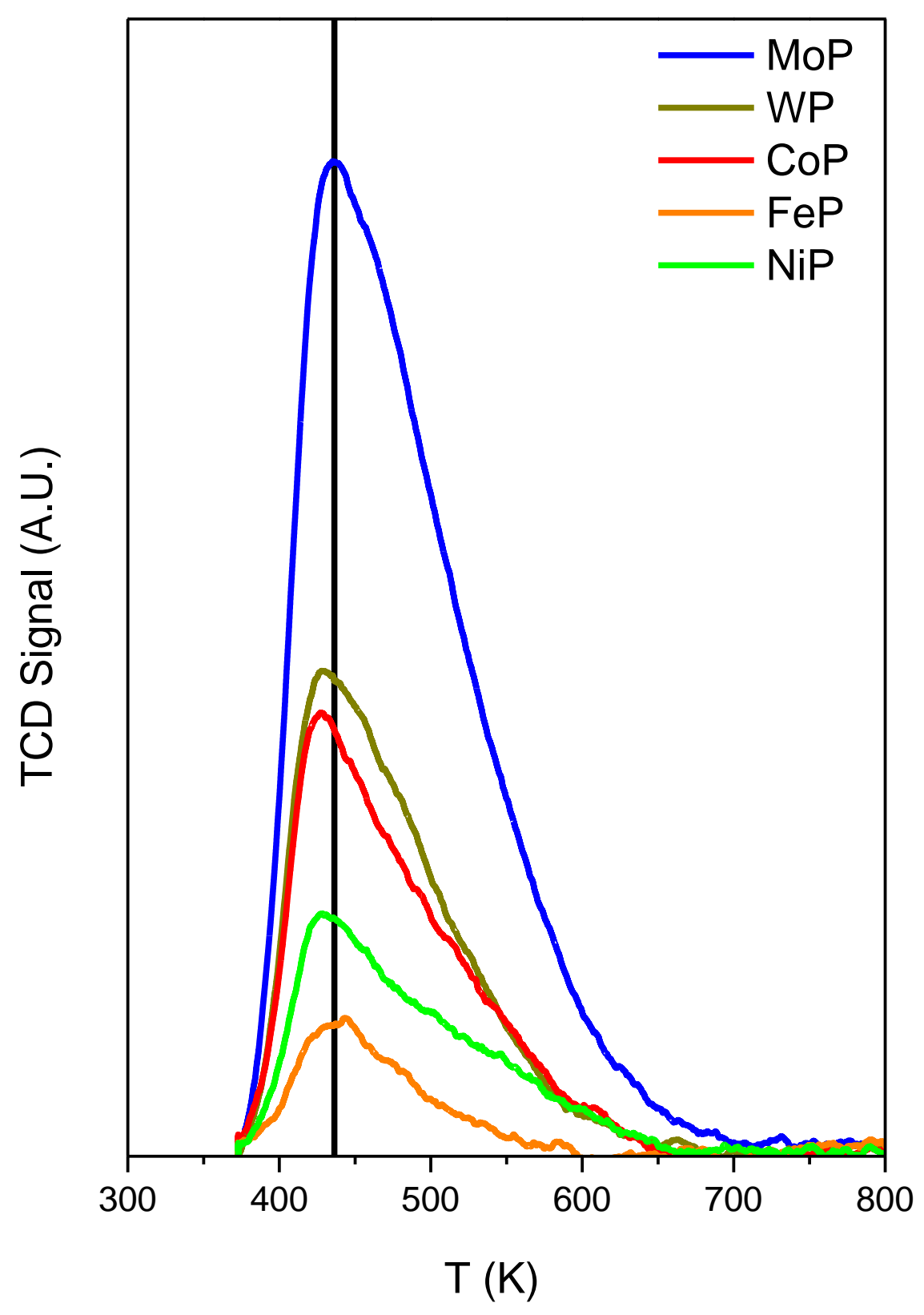

Figure 3 Temperature programmed ammonia desorption profiles for the reduced catalysts 

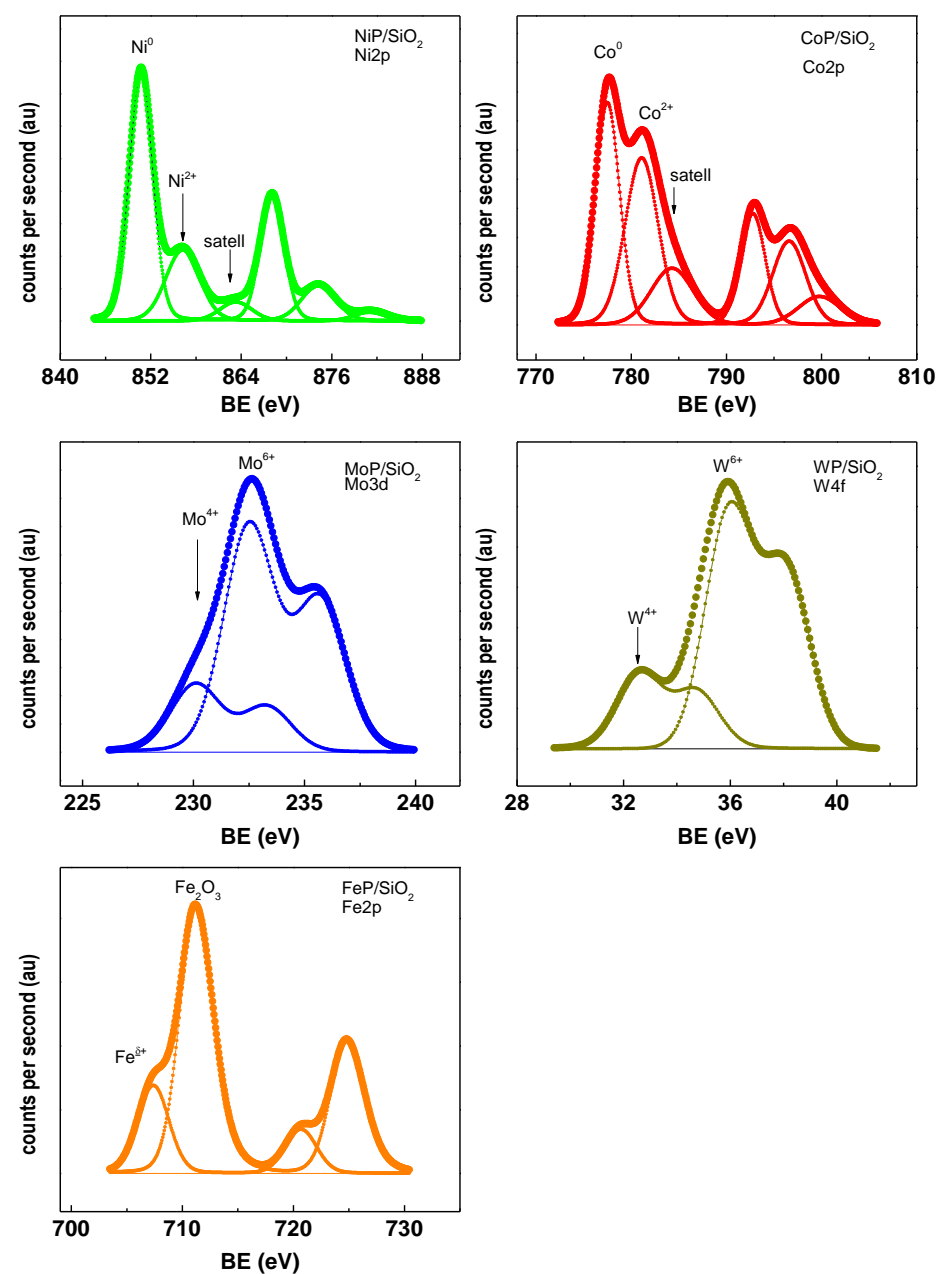

Figure 4 XPS spectra for reduced catalysts 

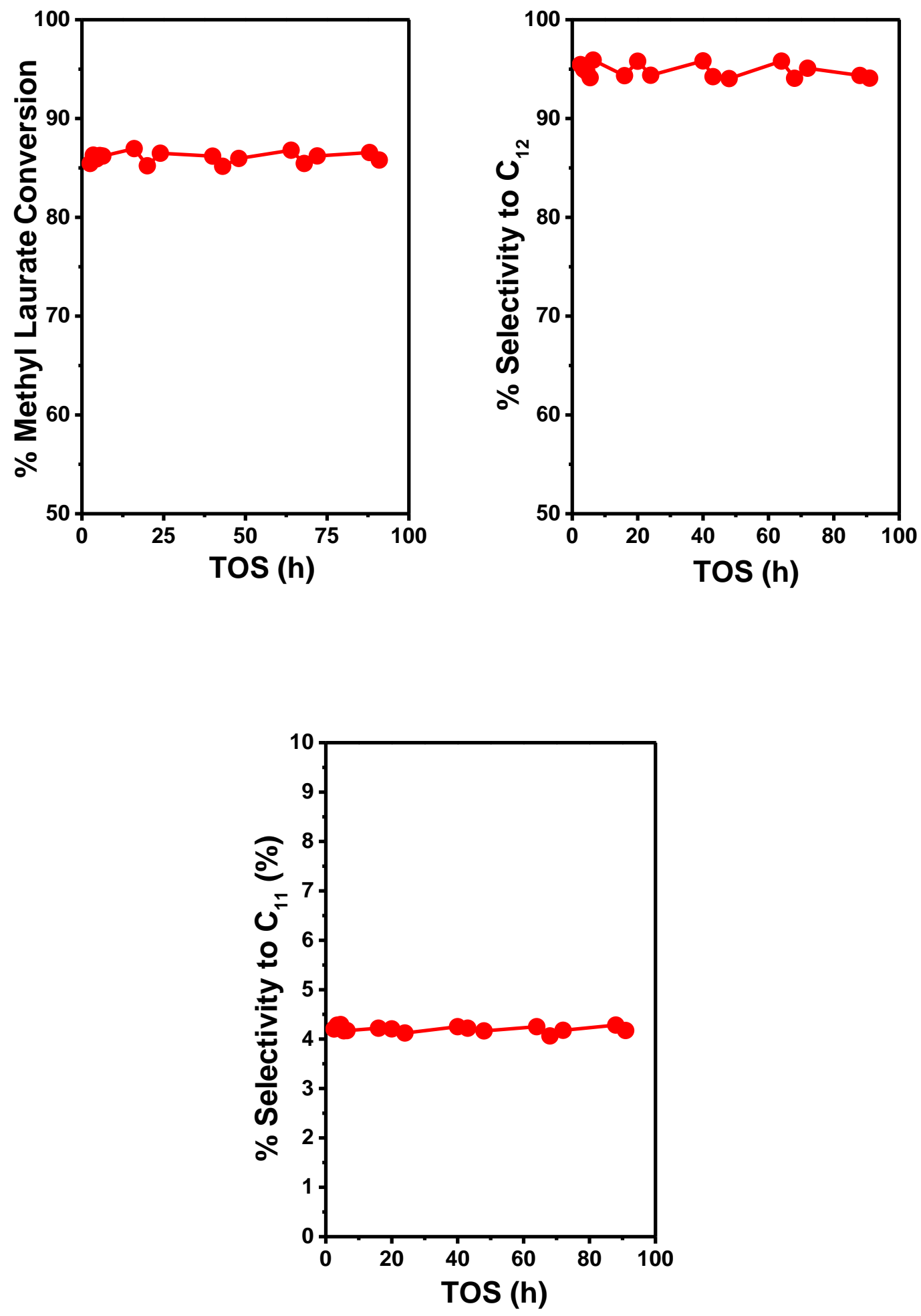

Figure 5 Stability test of the $\mathrm{MoP} / \mathrm{SiO}_{2}$ catalyst in the hydrotreatment of methyl laurate $\left(\mathrm{T}=673 \mathrm{~K}\right.$, catalyst $=3 \mathrm{~g}$, Liquid Flow $=0.3 \mathrm{~mL} \cdot \mathrm{min}^{-1}, \mathrm{P}=2.0$ $\mathrm{MPa}, \mathrm{H}_{2} /$ liquid $\left.(\mathrm{mol})=300\right)$ 